\title{
Serine/Threonine-Protein Kinase Sgk1
}

National Cancer Institute

\section{Source}

National Cancer Institute. Serine/Threonine-Protein Kinase Sgk1. NCI Thesaurus. Code C101561.

Serine/threonine-protein kinase Sgk1 (431 aa, $49 \mathrm{kDa}$ ) is encoded by the human SGK1 gene. This protein plays a role in both signaling in response to cellular stress and serine/threonine phosphorylation. 